\title{
A Theoretical Framework for Assessing Students' Cognitive Engagement through Computer-supported Collaborative Learning
}

\author{
Nurbiha A Shukor, Zaidatun Tasir, and Jamalludin Harun
}

\begin{abstract}
Online learning has been addressed as one of the emerging method of learning with multiple learning approaches. However, researchers raised the question whether the computer-mediated educational programmes as in online learning do meet the quality. They call for the investigation of the textual material being produced during online discussions to analyze critical thinking and interactivity. Several previous researches also managed to identify the degree of students' cognitive engagement and found that students' cognitive engagement are at the lower level. In the presented paper, a theoretical framework is proposed for the rationale of addressing the above issue.
\end{abstract}

Index Terms-Cognitive engagement; computer-supported collaborative learning environment; knowledge construction; online learning.

\section{INTRODUCTION}

Online learning has been addressed as one of the emerging method of learning with multiple learning approaches. However, Muirhead [1] raises the question whether the computer-mediated educational programmes as in online learning do meet the quality. He calls for the investigation of the textual material being produced during online discussions to analyze critical thinking and interactivity. It is also important to investigate the relationship between cognitive engagement attributes for the understanding of students' learning in online courses [2]. As being mentioned by Lipponen [3] in areas of CSCL itself, there is no grounding evidence that collaboration through networks is beneficial. Investigation on how different types of participation patterns impact learning and how do these aspects are related to CSCL with regard to students' discourse online discussion will provide better insight on the influence of CSCL for students' learning [3].

Several previous researches managed to identify the degree of students' cognitive engagement and found that students' cognitive engagement are at the lower level [4, 2, 5, $6,7]$. Hence, research has to be conducted to seek ways to boost their cognitive engagement towards the higher order of learning particularly in the Web based Multimedia Development subject which requires students' multiple skills for success learning. The complexity of the subject requires students to exert an amount of mental effort to solve the given problem [8].

On the other hand, computer-supported collaborative

Manuscript received July 9, 2012; revised August 29, 2012.

The authors are with Universiti Teknologi Malaysia. learning has evolved in many different dimensions over the past few years. This approach has been applied in several different subjects with the expectation that it would be able to boost the students' academic performances other than projecting the students in social skills such as solving problems, resolve arguments and peer-interacts.

Thus, this research suggests the implementation of computer-supported collaborative learning principles for the students to learn Web-based Multimedia Development subject via online to inculcate higher order cognitive engagement as required by the subject. Upon this approach, this research expected to observe the students' pattern of interaction for cognitive engagement, whether the students are able to construct knowledge at the higher level of cognitive engagement and how do these, impact their academic performances, as well as which CSCL principles contribute to students' cognitive engagement.

\section{PROCEDURE FOR PAPER SUBMISSION}

The theoretical framework of this research combines several ideas. Initially, the term 'cognitive engagement' is made transparent for future reference. Prior analyses have explained that computer-supported collaborative learning, CSCL, approach can support co-construction of knowledge $[3,9]$ and supports greater social interaction [9, 10]. Thus, CSCL approach is proposed for the purpose of enhancing students' cognitive engagement in online learning.

Next, a system needs to be developed that counters the principles of CSCL. Three-Phase Design (3PD) instructional design model [11] is used for developing the system used in this research. The model, as according to Sims [12]:

"The implication of applying the 3PD model is that the original functional system will always be subject to change, and that development environments need to schedule resources for the life-time of that course. The continual process of gathering and incorporating evaluation data caters for the sustainability of the course".

After going through the processes of building, enhancing, and maintaining in 3PD instructional design model, the core of this research, which is to analyze students' cognitive engagement will be carried out. Students' discussion scripts will be analyzed according to Van der Meijden's analytical framework [13]. His coding scheme has been repeatedly tested in his previous researches (see works by Kleine Staarman [14]).

Finally, the efficiency of the developed system will be evaluated with respect to students' level of cognitive 
engagement (can it excites the level of cognitive engagement to the higher degree), students' pattern of interactions and its' relationship with level of cognitive engagement, and students' academic performances.

The following sub-topics will provide greater insight on each elements of the proposed theoretical framework.

\section{A. Cognitive Engagement in Online Learning}

The definition of cognitive engagement is adapted from Zhu's [2] previous work. His definition of cognitive engagement is the students' attention to discussion messages, which can be observed from several postings behaviour [2]. According to Zhu [2], students' mental effort can be translated in activities such as seeking, interpreting, analyzing and summarizing information, critiquing and reasoning through various opinions and arguments, and making decisions. Respectively, the related activities are the characteristics of collaborative co-construction of knowledge [13]. Hence, cognitive engagement with this respect can also be understood as students' sustained mental effort for co-construction of knowledge while solving the given task.

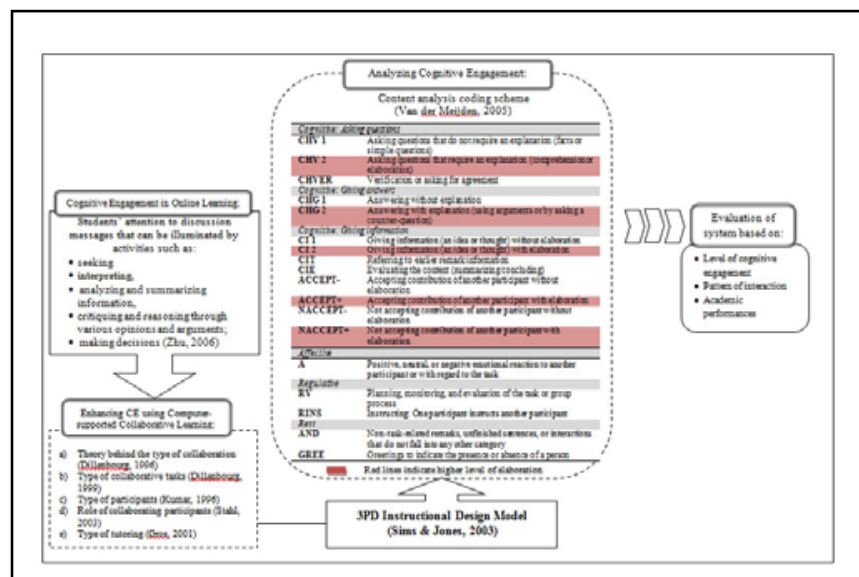

Fig. 1. The theoretical framework to investigate cognitive engagement in computer-supported collaborative learning environment.

\section{B. Enhancing Cognitive Engagement through Computer-supported Collaborative Learning}

Upon defining the context of cognitive engagement in this research, computer-supported collaborative learning is the suggested mediation to enhance cognitive engagement in online learning. Principles of CSCL are collected from varies researches. However, only five attributes will be experimented in this research. There are:

- theory behind the type of collaboration [15],

- type of collaborative tasks [16],

- type of participants [17],

- role of collaborating participants [18],

- type of tutoring [19].

\section{Three-Phase Design Instructional Design Model}

Rather than employing the effort of replacing the widely-used ADDIE (Analysis, Design, Develop, Implement, Evaluate) steps, the reason for coming up with Three-phase Design, 3PD is to welcome new interpretation of the overall idea of instructional design with respect to online teaching and learning [12]. Three-phase Design (3PD) model is pioneered by Sims and Jones [11] (see Figure 1) where it supports revision, enhancement and adaptability. The model emphasized on collaborating and ongoing works of the team over the phases. It allows analysis of instructional problems and immediate accurate solutions [20].

In relation to the instructional design, the model considers the following issues with respect to the online learners:

- the learner has the potential to advance and define their own essential knowledge based,

- the very uncertainty and lack of predictability of learning outcomes will be the key factor that adds value to a learning community,

- emergent systems will provide the necessary triggers to enhance knowledge and understanding, and

- emergent learning will be one of the critical triggers to unleash individual creativity [21].

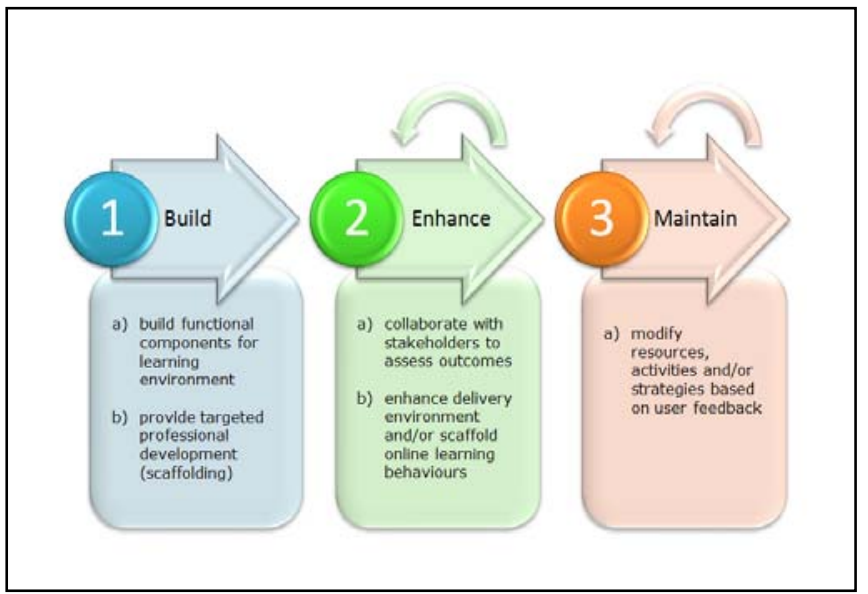

Fig. 2. The Three-Phase Design Model by Sims and Jones [11] being adapted from Sims [12].

\section{Analyzing Cognitive Engagement}

Van der Meijden's work is to analyze social knowledge construction in CSCL environment based on the attributes of 'elaboration'. He values both cognitive and affective dimensions for an effective collaborative knowledge building and thus designed the analytical framework combining both dimensions [13].

The analytical framework by Van der Meijden [13] has being previously used by Schellens and friends [6], who reported that students rarely reach the higher level of knowledge construction. Van der Meijden [13], on explaining his work, he reported that students' level of knowledge construction in asynchronous and synchronous discussion varies from high to low [13]. These findings are similar to Zhu's report on students' cognitive engagement in four online discussions [2]. He indicated that post graduate students are likely being able to communicate at a higher level of cognitive engagement as compared to the undergraduates [2].

Addressing cognitive engagement as students' sustained mental effort for co-construction of knowledge will be useful particularly in online learning context where observation is almost an impossible way of investigation. Students' textual material being produced during discussion can serve as a representative of their mental activities and interactivity [1].

\section{E. Evaluation of Web-based Learning's Efficiency}

Reports by Sims and his friends [20] indicated that students value the diversity of assessment and that 
assessment by regularity of postings did not necessarily indicate the quality. Schankman also added that a program would be best assessed from several perspectives; not only by grades and test scores [22]. Thus, evaluation of the efficiency of the developed CSCL website will be based on three attributes; level of cognitive engagement, pattern of interaction, and students' academic performances.

1) Level of Cognitive Engagement

Previous researches indicated that students level of cognitive engagement varies from high to low [2, 13]. In fact, there also findings that students' level of cognitive engagement remains low despite the given mediation [4, 7]. The efficiency of the given mediation (CSCL environment) will be transparent if the developed website is able to excite the students' level of achievement from low to higher degree. Higher degree of cognitive engagement is indicated by students achieving the elaboration level as indicated in Table I.

TABLE I: CONTENT ANALYSIS CODING SCHEME THAT INDICATES HigHER DEGREE OF KNOWLEDGE CONSTRUCTION

\begin{tabular}{|l|l|}
\hline \multicolumn{2}{c|}{ Content Analysis Coding Scheme } \\
\hline CHV 2 & $\begin{array}{l}\text { Asking questions that require an explanation } \\
\text { (comprehension or elaboration) }\end{array}$ \\
\hline CHG 2 & $\begin{array}{l}\text { Answering with explanation (using arguments or by asking a } \\
\text { counter-question) }\end{array}$ \\
\hline ACCEPT+ & $\begin{array}{l}\text { Accepting contribution of another participant with } \\
\text { elaboration }\end{array}$ \\
\hline NACCEPT+ & $\begin{array}{l}\text { Not accepting contribution of another participant with } \\
\text { elaboration }\end{array}$ \\
\hline CI 2 & Giving information (an idea or thought) with elaboration \\
\hline
\end{tabular}

\section{2) Pattern of Interaction}

Types of online interactions vary. Sharp and Huett [23] listed out that there are student-student, student-content, student-instructor [24], learner-interface [25], learner-feedback [26] and vicarious interaction [27]. Although CSCL values all types of interaction, emphasized is on peer interactions (student-student interaction); the context where knowledge construction process occurs [16]. According to Anderson's Equivalency Theorem [28], deep and meaningful learning is possible if one of the main forms of interaction, that is student-student, student-content, or student-teacher interaction is at high level.

For online learning, investigating the depth of peer interaction will provide beneficial insight on whether the learning environment is efficient. This is due to the fact that although technology supports networking in online learning, students remain learning alone where the students do not favor the used of discussion boards, emails and online chats [23]. As peer interaction for negotiation of meaning itself indicates social construction of knowledge [29], investigating the depth of peer interaction by performing content analysis to the textual material that they produced will provide the information as to which degree does the interaction had undergone [1].

\section{3) Academic Performances}

Socio-cultural theory suggests that human's thought cannot be represented by speaking as they are "boundly inter-related" [30]. Thus, any possibility of observing the human mental capacities has to be conducted to support the thinking [30]. Investigating the impact of mediation to students' performance in test is also useful to support the information on the mediation's efficiency. In socio-cultural theory, Lantolf [30] asserts that:

".. human behavior results from the integration of socially and culturally constructed forms of mediation into the human activity".

\section{CONCLUSION}

The proposed theoretical framework illustrated the overall picture of how the research of investigating students' cognitive engagement in online learning will be carried out. The contribution of the research would be clarifying whether CSCL environment would enhanced students' level of cognitive engagement towards the higher degree or conversely.

\section{ACKNOWLEDGMENT}

The authors would like to thank Universiti Teknologi Malaysia (UTM) and Ministry of Higher Education (MoHE) Malaysia for their support in making this project possible. This work was supported by Research University Grant (Q.J130000.7116.00J83) initiated by UTM and MoHE.

\section{REFERENCES}

[1] B. Muirhead, "Enhancing Social Interaction in Computer-mediated Distance Education,” Educational Technology \& Society, vol. 3, no.4, 2000, pp. 1-11.

[2] E. Zhu, "Interaction and cognitive engagement: An analysis of four asynchronous online discussions,” Instructional Science, vol. 34 no. 6 , 2006, pp. 451-480.

[3] L. Lipponen, “Exploring foundations for computer-supported collaborative learning,' Proceedings of the conference of Computer Support for collaborative Learning: Foundations for a CSCL community, 2002, pp. 72-81.

[4] C. McLoughlin and J. Luca, “Cognitive Engagement and Higher Order Thinking through Computer Conferencing: We Know Why but Do We Know How?,” In A. Herrmann and M.M. Kulski (Eds), Flexible Futures in Tertiary Teaching, Proceedings of the $9^{\text {th }}$ Annual Teaching Learning Forum, February 2000, Perth: Curtin University of Technology.

[5] T. Schellens and M. Valcke, "Collaborative Learning in asynchronous discussion groups: What about the impact on cognitive processing?," Computers in Human Behaviour, vol. 21, 2005, pp. 957-975.

[6] T. Schellens, V. H. Keer, D. B. Wever, and M. Valcke, "Student elaborations and knowledge construction in asynchronous discussion groups in secondary education,” Proceedings of the 8th international conference on International conference for the Learning Sciences - vol. 2008, pp. 413-415.

[7] W. W. A. Ma, "Computer-supported Collaborative Learning and Higher Order Thinking Skills: A Case Study of Textile Studies,” Interdisciplinary Journal of E-learning and Learning Objects. vol 5, 2009, pp. 145-167.

[8] S. Joung, "Product-based computer skill training to reduce learner's cognitive load,” In C. Crawford et al. (Eds.) Proceedings of Society for Information Technology \& Teacher Education International Conference 2005, pp. 3249-3250.

[9] E. Lehtinen, K. Hakkarainen, L. Lipponen, M. Rahikainen, and H. Muukkonen, "Computer Supported Collaborative Learning: A review of research and development," The J.H.G.I Giesbers Reports on Education, vol 10, 1999.

[10] S. Paavola, L. Lipponen, and K. Hakkarainen, "Epistemological Foundations for CSCL: A Comparison of Three Models of Innovative Knowledge Communities," Proceedings of the Computer-supported Collaborative Learning, 2002 Conference, Hillsdale, N.J.; Erlbaum.

[11] R. Sims and D. Jones, "Where practice informs theory: Reshaping instructional design for academic communities of practice in online 
teaching and learning," Information Technology, Education and Society, vol. 4 Num 1, 2003, pp. 3-20.

[12] Sims, R. "From three-phase to proactive learning design: Creating effective online teaching and learning environments,” In J. Willis (Ed), 2008, Constructivist Instructional Design (C-ID): Foundations, Models, and Practical Examples.

[13] H. Van der Meijden, "Knowledge Construction through CSCL: Student Elaborations in synchronous, asynchronous, and three-dimensional learning environments,” 2005, Duiven: drukkerij Tamminga.

[14] J. Kleine Staarman, K. Krol, and H. Van Der Meijden, "Peer interaction in three collaborative learning environments," Journal of Classroom Interaction, vol. 40 Num 1, 2005

[15] P. Dillenbourg, M. Baker, A. Blaye, and C. O'Malley, “The evolution of research on collaborative learning,” In E. Spada \& P. Reiman (Eds) Learning in Humans and Machine: Towards an interdisciplinary learning science, 1996, pp. 189-211. Oxford: Elsevier.

[16] P. Dillenbourg, "What do you Mean by Collaborative Learning?," In Dillenbourg P. (Ed.). Collaborative-Learning: Cognitive and Computational Approaches 1999, pp. 1-19. Oxford: Elsevier.

[17] V. Kumar, "Computer-Supported Collaborative Learning: Issues for Research,” Paper presented at Graduate Symposium, 1996 University of Saskatchewan.

[18] G. Stahl, "Meaning and interpretation in collaboration," In: Proceedings of Computer Support for Collaborative Learning (CSCL '03), 2003, Bergen, Norway.

[19] B. Gros, "Instructional design for computer-supported collaborative learning in primary and secondary school," Computers in Human Behaviour. vol 17, 2001, pp.439-451.

[20] R . Sims, L. Mikkelsen, and P. Iji, "Poultry production online: Where broilers and layers encounter virtual pedagogy,” Proceedings Ascilite Melbourne, 2008. Pp. 932-941.

[21] E. Kays, \& R. Sims, "Reinventing and reinvigorating instructional design: A theory for emergent learning," Proceedings of the 23rd annual ascilite conference: Who's learning? Whose technology?, 2006, pp. 409-412.

[22] L. Schankman, "Holistic evaluation of an academic online programme,” 20th Annual Conference on Distance Teaching and Learning, Madison, Wisconsin, August 2004.

[23] J. Sharp and Huett "Importance of Learner-Learner Interaction in Distance Education,” Information Systems Education Journal, vol
4 (46), 2006, [Online]. Available: http://isedj.org/4/46/. ISSN 1545-679X. (A preliminary version appears in The Proceedings of ISECON 2005: §2323. ISSN: 1542-7382.)

[24] M. Moore, “Three types of Interaction,” American Journal of Distance Education, Vol 3 Num 2, 1989, pp. 1-6.

[25] D. C. Hillman, D. J. Willis, \& C. N. Gunawardena, "Learner-interface interaction in distance education: An extension of contemporary models and strategies for practitioners," The American Journal of Distance Education, vol. 8 (2), 1994, pp.31-42.

[26] Northrup, Pam T. and Karen L. Rasmussen, “Designing a Web-Based Program: Theory to Design,” Paper presented at the annual conference of the Association for Educational Communications and Technology, Long Beach, CA: February 2000.

[27] Leah A. Sutton, "The Principle of Vicarious Interaction in Computer-Mediated Communications," International Journal of Educational Telecommunications vol. 7, no. 3, 2001, pp. 223-242.

[28] T. Anderson, "Getting the mix right again: an updated and theoretical rationale for interaction," International Review of Research in Open and Distance Learning, October 2003.

[29] D. H. Jonassen, "Designing constructivist learning environments," In Duffy, T. M., Lowyck, J., and Jonassen, D. H. (Eds), The Design of Constructivistic Learning Environments: Implications for Instructional Design and the Use of Technology, Heidelburg, 1993, FRG: Springer-Verlag.

[30] J. P. Lantolf, “Introducing sociocultural theory,” In J. P. Lantolf, (Ed.), Sociocultural theory and second language learning, 2000, pp. 1-26, Oxford: Oxford University Press.

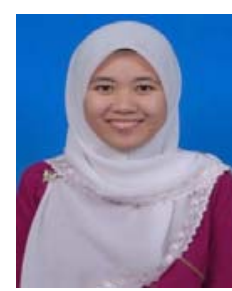

Nurbiha A Shukor was born on $15^{\text {th }}$ March 1986 in Muar Johor, Malaysia. She received her primary education at SK Convent Muar and continued her secondary education at SMK Dato’ Sri Amar Diraja Muar. She then studied A-level at Perak Matriculation College and received her degree in Chemistry and Science Computer Education from Universiti Teknologi Malaysia in 2009.

She is currently doing her $\mathrm{PhD}$ in Educationa Technology at Universiti Teknologi Malaysia and a Tutor at the same university. Her research interest is related to computer learning, computer-supported collaborative learning and online learning. 